\title{
Female Adnexal Tumour of Probable Wolffian Origin (FATWO): Review of the Literature
}

\section{Female adnexal Tumour of probable Wolffian Origin (FATWO): Literaturübersicht}

\section{(ㄷ) (i) 웅 $\ominus$}

\author{
Authors \\ Achim Wöckel ${ }^{1}$, Daniel Herr ${ }^{1}$ \\ Affiliations \\ 1 Department of Obstetrics and Gynaecology, Würzburg \\ University Medical Centre, Würzburg, Germany \\ 2 Department of Pathology, Universitiy of Würzburg and \\ Comprehensive Cancer Center (CCC) Mainfranken, \\ Würzburg, Germany \\ 3 Institute of Pathology, Ludwig-Maximilians-University \\ Munich, Munich, Germany \\ 4 Department of Diagnostic Radiology, Würzburg University \\ Medical Centre, Würzburg, Germany
}

Theresa Barbara Hübner ${ }^{1}$, Michael Schwab ${ }^{1}$, Elena Hartmann², Doris Mayr ${ }^{3}$, Annette Thurner ${ }^{4}$, Thorsten Bley ${ }^{4}$,

Key words

FATWO, adnexal tumour, borderline tumour

Schlüsselwörter

FATWO, Adnextumor, Borderlinetumor

$$
\begin{array}{ll}
\text { received } & 21.7 .2018 \\
\text { revised } & 11.9 .2018 \\
\text { accepted } & 18.9 .2018
\end{array}
$$

\section{Bibliography}

DOI https://doi.org/10.1055/a-0746-8985

Geburtsh Frauenheilk 2019; 79: 281-285 @ Georg Thieme Verlag KG Stuttgart · New York | ISSN 0016-5751

\section{Correspondence}

Theresa Barbara Hübner

University Hospital

Josef-Schneider-Straße 4, 97080 Würzburg, Germany

huebner_t1@ukw.de

Deutsche Version unter:

https://doi.org/10.1055/a-0746-8985

\section{ABSTRACT}

FATWO (female adnexal tumour of probable Wolffian origin) denotes a rare tumour of the female adnexa which has been described in nearly 80 cases worldwide and which presumably originates in the remains of the Wolffian ducts. In 10 to 20 percent of patients, a metastasis or recurrence was seen subsequently and for this reason, a malignant potential is attributed to the FATWO. Because of the small number of cases, there is no clear therapeutic recommendation. The method of choice currently is surgical treatment with hysterectomy and adnexectomy. The benefit of radio- and chemotherapies is not clear and a small number of treatment attempts with imatinib have been made in cases of CD117 positivity or treatment attempts on an endocrine basis. This work provides an overview of the literature on epidemiology, imaging and histopathological diagnostic features as well as therapeutic options of this same tumour form.

\section{ZUSAMMENFASSUNG}

FATWO (female adnexal tumour of propable Wolffian origin) bezeichnet einen seltenen Tumor der weiblichen Adnexe, der weltweit in knapp 80 Fällen beschrieben wurde und dessen Ursprung vermutlich in den Residuen der Wolff'schen Gänge liegt. Bei 10 bis 20 Prozent der Patientinnen zeigte sich im Verlauf eine Metastasierung oder ein Rezidiv, weshalb dem FATWO ein malignes Potenzial zugeschrieben wird. Aufgrund der kleinen Fallzahl existiert keine klare Therapieempfehlung. Methode der Wahl ist derzeit eine operative Sanierung mit Hysterektomie und Adnexektomie. Der Nutzen von Radiound Chemotherapien ist nicht eindeutig, vereinzelt wurden Therapieversuche mit Imatinib bei CD117-Positivität oder Therapieversuche auf endokriner Basis unternommen. Diese Arbeit zeigt eine Literaturübersicht über Epidemiologie, bildgebende und histopathologische Diagnosemerkmale sowie Therapieoptionen dieser seltenen Tumorform. 

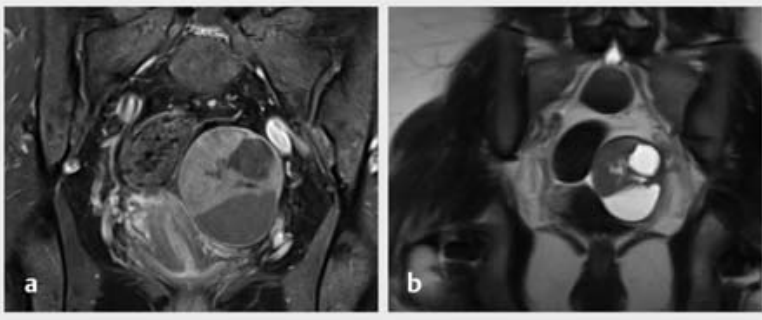

- Fig. $1 \mathrm{MRI}$ of pelvis in the coronal plane. Mass in the left lower abdomen dorsolaterally between the uterus and left ovary. The "rim sign" is seen (hyposignal margin edging the tumour). a coronal fat-saturated T1-weighted sequence after i.v. administration of contrast medium; b coronal T2-weighted sequence.
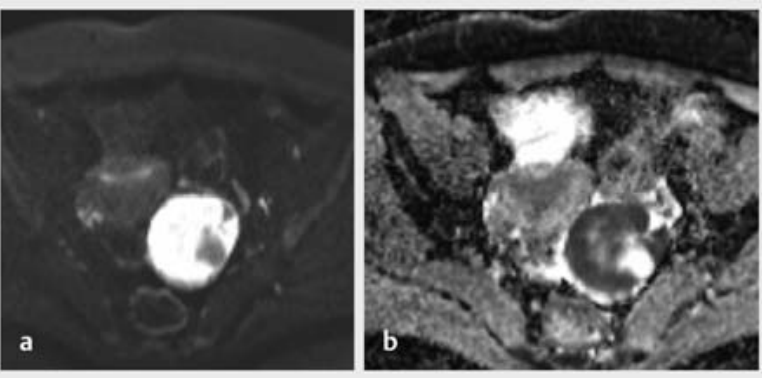

- Fig. 2 MRI of pelvis in the transverse plane. Mass in the left lower abdomen, characteristic of the high degree of cellularity of the FATWO, is seen in the left image (a) the tumour hyperintense in the DWI sequence with high b values (b800); right (b) correspondingly low signal in the ADC map.

\section{Introduction}

What is known as a female adnexal tumour of probable Wolffian origin (FATWO) is a very rare form of female adnexal tumour. Worldwide, only about 80 cases have been described in the literature to date [1]. Most of these cases demonstrated benign behaviour, however some also had an aggressive clinical course and for this reason, the FATWO is currently said to have at least a low malignant potential. In December 2016, a 33-year-old patient, nulligravida with infertility and unclear adnexal findings, presented to our clinic and the conclusive diagnostic procedures revealed a FATWO. Using this clinical case, a review of the literature on the diagnosis, therapy and prognosis of this disease will be provided below.

\section{Epidemiology and Localisation}

A tumour form of the female adnexa whose origin was suspected to be in the remains of the Wolffian ducts due to the morphological aspect was described for the first time in 1973 by Kariminejad et al. For embryological reasons, these are located on the path between the ovarian hilus over the mesosalpinx and the lateral uter- ine wall to the upper outer third of the vagina. These tumours appear most often in the parametrium or in the tube [2]; cases in which a FATWO occurred in the ovary have also been described [3]. A review by Heatly et al. from 2009 investigated 63 cases worldwide. In $11.1 \%$ (7 patients) of the patients, there were recurrences or remains of the tumour and 3 patients (4.8\%) died from the disease [4]. The age of onset of the disease is between 15 and 81 years and the median is 50 years [5].

\section{Diagnosis}

One Japanese publication investigated 5 cases of a FATWO in which, retrospectively evaluated, the preoperative imaging using magnetic resonance imaging (MRI) was able to give an indication of the tumour entity. Here, smooth muscle cells are histologically present in the FATWO which appear in the T2 weighing of the MRI image as a hyposignal margin which could also be present in other benign ovarian processes but which are not present in the case of an ovarian carcinoma, by contrast [6]. Our patient's MRI images were examined once again following receipt of the histopathological results for the characteristics mentioned, and the morphological criteria on the imaging described could also be found in our case.

Following suspicion of a cystic-solid mass of the adnexa on ultrasound with unremarkable tumour markers (Ca-125 at $23.1 \mathrm{U}$ / $\mathrm{ml}, \mathrm{CEA}$ at $0.3 \mu \mathrm{g} / \mathrm{l})$, MRI imaging of the pelvis was performed for surgical planning, due to the unusual structure of the mass.

In the left adnexal space, dorsolaterally between the uterus with unremarkable configuration and the left ovary, a lobulated mixed cystic-solid mass measuring $6.0 \times 5.0 \times 5.6 \mathrm{~cm}$ was seen. A 1 -mm wide hypointense margin with significant contrast medium enrichment was seen in the T2 weighting ( $\bullet$ Figs. 1 and 2 ).

Following the intravenous administration of contrast medium, the solid portions of the tumour demonstrated moderate uptake of contrast medium and appear to have significantly impaired diffusion as an indication of a high degree of cellularity in the diffusion-weighted image.

An indication was made for laparoscopic tumour removal and chromopertubation. A half-fist-sized, cystic, left paratubal mass was seen intraoperatively in the region of the lesser pelvis ( $\triangleright$ Fig. 3). Meanwhile, tubes and ovaries bilaterally appear unremarkable. On the right side, chromopertubation resulted in the prompt leakage of blue dye; this did not occur on the left. During laparoscopic extirpation of the findings using a retrieval pouch, partly liquid, partly tallowy secretion drained into the pouch.

Histologically, FATWOs can display a diverse picture; the coexistence of various components is often described, such as solid or diffuse growth patterns with scattered vacuoles or tubules. Cribriform growth patterns are also mentioned, such as tubular or cystic structures. A fibrous capsule which may be permeated with neoplastic cells frequently surrounds the tumour. "Blaustein's Pathology of the female genital tract" indicates the following immunohistochemical characteristics for the FATWO: positivity for CD10 and cytokeratins (the pan cytokeratin antibodies AE1/3 and Cam5.2 as well as cytokeratin 7). Moreover, vimentin as well as calretinin and inhibin as markers of the sex cord stroma are pos- 
itive in most cases, whereas reactivity for the oestrogen and progesterone receptor is described more rarely $[7,8]$.

With regard to the cytomorphology, the tumour cells appeared partially epithelioid, partially spindle-cell-like with round to oval, relatively homogeneous cell nuclei and nucleoli which are only focally weakly recognisable ( $\bullet$ Fig. 4 ). The additional immunohistochemical investigations revealed consistent positivity for inhibin and irregular, diffuse reactivity for SF1 as well as partial positivity for calretinin and CD56. In the synaptophysin stain, individual tumour cells at most revealed rather weak reactivity and the chromogranin immunohistochemistry turned out to be negative. In addition, positivity of the tumour cells for CD99 and WT1 was seen. The pan cytokeratin marker $A E 1 / 3$ also reacted positively over larger sections in the tumour cells; moreover there was also significant positivity for cytokeratin 19 , whereas the stains for cytokeratin 7 and EMA were negative, and also for actin. There was also focal reactivity of the tumour for CD10. The tumour cells remained negative in the stain for the oestrogen receptor and the stain for the progesterone receptor was weakly positive only at a few sites. The proliferative activity (Ki67 immunohistochemistry) was very low $(<5 \%)$. Additional immunohistochemistry performed for CD117/c-kit turned out to be negative in the tumour cells.

In addition, another mutation analysis with the aid of Next Generation Sequencing (Ion Torrent PGM) using the Ion AmpliSeq ${ }^{\mathrm{TM}}$ Cancer Hotspot Panel v2 was performed to determine the c-KIT mutation status. The evaluation of the exons of the c-KIT gene (exon 9, 11, 13 and 17) revealed no genetic alterations corresponding to wild-type unmutated sequences.

Moreover, the FOXL2 mutation normal (>90\%) for adult GCT was also tested and could not be proven.

As initially suspected in our case, an adult granulosa cell tumour (GCT) which demonstrates many morphological and immunohistochemical parallels to the FATWO was considered as a differential diagnosis. In addition to the nuclear grooves which can often histologically be found more clearly in the case of GCTs and the more rare strong cytokeratin positivity, the clinical picture in particular is critical, especially the exact primary localisation of the tumour outside of the ovary in the region of the former Wolffian duct system. Indeed, only isolated parametrial adult granulosa cell tumours are described in the literature, however these are true rarities, with 8 cases described in the literature [9]. Negative findings in the FOXL2 mutation analysis makes an adult granulosa cell tumour additionally unlikely. In a few cases, FATWOs were tested for c-kit positivity (CD117) and mutations in the c-kit gene which did not generate any consistent results [5, 10-12].

\section{Therapy}

Because of the rarity of this type of tumour, there are no clear therapeutic recommendations. Currently, surgical tumour removal is the method of choice. This generally involves a hysterectomy with bilateral salpingo-oophorectomy, but in some cases, a fertility-preserving approach is selected, depending on the patient's age and life situation. However, the risk of recurrence appears to be higher here. Surgical therapy was performed via laparotomy in nearly all cases [13].

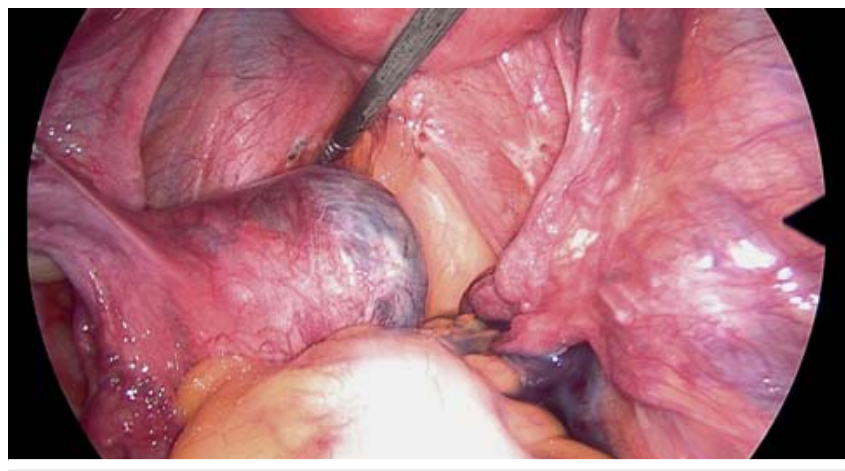

- Fig. 3 Intraoperative image of the FATWO: the approximately half-fist-sized mass is seen at the tip of the grasping forceps in the left parametrium, dorsal to the tube. The uterus is at the top of the image.

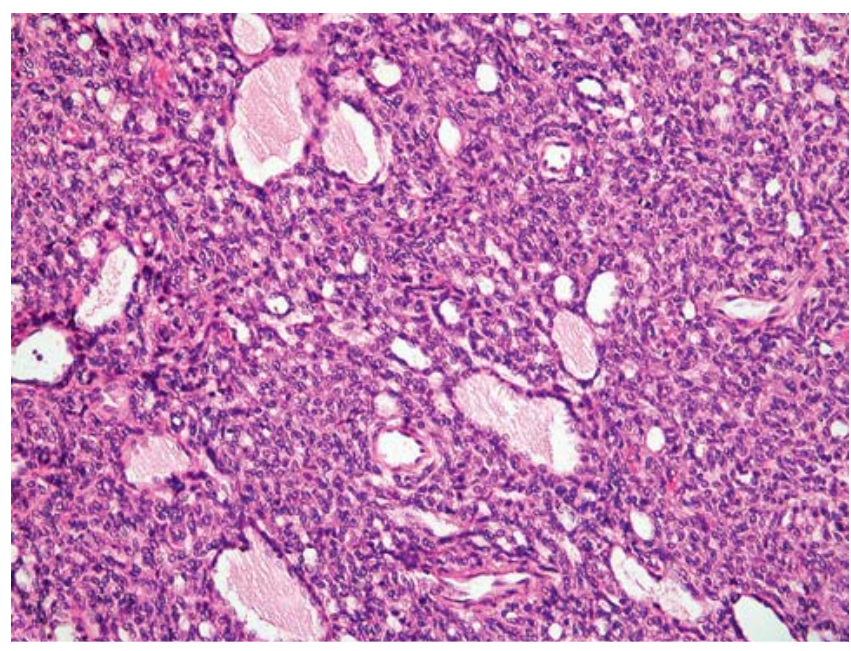

- Fig. 4 Microscopic image of the FATWO, HE stain, magnification $1: 200$; the reticulated, perforated growth pattern of the tumour and the high degree of cellularity can be easily identified.

After the histological result was received, our patient underwent staging using computed tomography of the chest and abdomen. This revealed no evidence of the formation visceral or lymphogenic metastasis. In the liver, a hypodense lesion was seen which was classified as a haemangioma on ultrasound upon further clarification. Given the patient's marked existing desire for a child, a left-sided salpingectomy was initially discussed with the patient. The execution of this surgery histopathologically revealed another 1-mm left paratubal portion of tumour in the region of the mesosalpinx. The patient was advised to undergo close follow-up monitoring as well as completion surgery after completing her family. In early June 2017, the patient presented to us with a spontaneous, intact early pregnancy. In February 2018, the patient had an uncomplicated, spontaneous delivery at $41+0$ weeks of pregnancy via spontaneous onset of labour. The completion surgery was once again recommended, however the patient did not currently want this since she still had not completed her family. 
Adjuvant radiotherapy or platinum-based chemotherapy is described for only a few cases (three patients in each case); one patient in each group developed a recurrence [3].

In the few reported cases of a local recurrence, top priority appears to be given to surgical tumour debulking, while chemotherapy and radiation therapy are considered to be of only minor benefit, with the combination of a platinum derivative with paclitaxel appearing to be the most effective $[5,10,12]$.

Cisplatin/cyclophosphamide, etoposide/ifosfamide/carboplatin, cisplatin/paclitaxel, carboplatin/paclitaxel with leuprorelin and irinotecan mono were administered as chemotherapy in the event of recurrence (10 reported cases). There is no detailed information in the published cases regarding radiation therapy.

Endocrine treatment attempts with leuprorelin concurrently with chemotherapy or medroxyprogesterone acetate (MPA) were not able to prevent disease progression, despite hormone receptor positivity [14].

In three of the four published cases in which immunohistochemical c-kit positivity (CD117) was demonstrated, imatinib, a tyrosine kinase inhibitor, was used analogously for c-kit-positive gastrointestinal tumours.

Steed et al. describe the case of a patient who, following repeat surgeries for recurrences and various chemotherapy regimens, demonstrated a radiological response on imatinib. Because of unclear lower abdominal pain, the patient underwent another exploration and tumour resection which revealed no tumour macroscopically. Histopathologically, areas of necrosis in the tumour tissue were seen which were interpreted as a potential therapeutic response. Postoperatively, the imatinib therapy was continued and the follow-up revealed the patient to be clinically free of recurrence after 10 months [5].

In another patient, the absence of tumour was not able to be achieved surgically in the case of a recurrence and after 4 months of imatinib therapy, progression was noted. Subsequent chemotherapy with paclitaxel $\left(180 \mathrm{mg} / \mathrm{m}^{2}\right)$ and carboplatin (AUC5) q21d revealed a good response and a clear reduction in tumour size after 10 cycles [12].

In the case of the third reported patient, imatinib was used for 6 months following the surgery for recurrent disease; the further clinical course is not reported in the study of Syriac et al. [10].

\section{Prognosis}

The literature reports recurrences and the formation of metastases, especially pulmonary and hepatic, in $10-20 \%$ of cases. An important criterion for assessing the risk of recurrence appears to be the complete tumour resection with salpingo-oophorectomy and hysterectomy. The median time of recurrence is about 48 months, however recurrences were observed during the period of 13-96 months and even later in some isolated cases [12].

As investigated by Heatly et al., three of the seven patients who experienced a recurrence or residual tumour died $(4.8 \%$ of the 63 cases listed) of the disease [4].

By contrast, more current data from Kwon et al. from 2016 present 21 cases worldwide in which a tumour recurrence in the liver, pelvis, appendix [15], peritoneum or omentum is reported [1]. Of these 21 cases of a malignant FATWO currently known, there is a documented tumour implantation in 15 cases in a period of up to 8 years after the initial disease. In 8 patients, tumour implantation was already present at the initial surgery and 3 of these patients demonstrated a recurrence or metastasis within the first year after surgery. The R0-resected patients without tumour implantations consistently did not demonstrate any recurrence in the scope of the work [14]. A prediction with regard to the clinical course is not currently possible either due to the clinical picture or by means of the histological tumour characteristics, although there are indications of a correlation between high mitotic activity and risk of recurrence $[3,16]$.

\section{Summary}

FATWO represents a rare form of female adnexal tumour which likely originates in the remains of the Wolffian ducts. After metastasis or recurrences appeared in a portion of the cases described, the FATWO was considered to have a certain potential for malignancy. From a histopathological perspective, an adult granulosa cell tumour, which can be differentiated from the FATWO by immunohistochemical features and mutation analyses, should be considered as a differential diagnosis. Indications from imaging performed can also help in making a diagnosis.

Because of the rarity of this disease, there are case reports and reviews which, however, due to the low number of cases, do not permit any universal statements and conclusions regarding which therapeutic measures should be recommended. A surgical option has become established, also in the event of a recurrence, with tumour resection including hysterectomy and bilateral salpingooophorectomy. The role of chemo- and radiotherapy cannot be assessed to date; platinum- and taxane-based regimens appear to have an advantage over other substances. An individual treatment attempt with imatinib in the case of $C D-117$ positivity of the tumour can be considered. For more information regarding therapeutic and diagnostic measures, further analyses of cases are needed.

The case we reported supplements the few cases in the literature in which the c-kit status was examined immunohistochemically as well as genomically and a preoperative MRI of the pelvis was performed.

\section{Conflict of Interest}

The authors declare that they have no conflict of interest.

\section{References}

[1] Kwon M], Yun MJ, Kim MK. A female adnexal tumor of probable Wolffian origin showing positive 0-6-methylguanine-DNA methyltransferase methylation. Obstet Gynecol Sci 2016; 59: 328-332

[2] Kariminejad MH, Scully RE. Female adnexal tumor of probable Wolffian origin. A distinctive pathologic entity. Cancer 1973; 31: 671-677

[3] Ramirez PT, Wolf JK, Malpica A et al. Wolffian duct tumors: case reports and review of the literature. Gynecol Oncol 2002; 86: 225-230

[4] Heatley MK. Is female adnexal tumour of probable wolffian origin a benign lesion? A systematic review of the English literature. Pathology 2009; 41: 645-648 
[5] Steed H, Oza A, Chapman WB et al. Female adnexal tumor of probable wolffian origin: a clinicopathological case report and a possible new treatment. Int J Gynecol Cancer 2004; 14: 546-550

[6] Sakai M, Abiko K, Matsumura N et al. Two cases of Wolffian tumor with novel magnetic resonance imaging findings reflecting characteristic pathology. J Obstet Gynaecol Res 2016; 42: 1046-1051

[7] Nann D, Gahlen S, Keul HG et al. [Tumor of the mesosalpinx with unclear differentiation]. Pathologe 2016; 37: 84-87

[8] Kurman RJ, Hedrick Ellenson L, Ronnett BM, eds. Blaustein's Pathology of the female genital Tract. Berlin, Heidelberg, New York: Springer; 2011

[9] Czernobilsky B, Lifschitz-Mercer B, Trejo L et al. Granulosa cell tumor of the broad ligament: report of a case with emphasis on the differential diagnosis with female adnexal tumor of probable Wolffian origin. Int J Surg Pathol 2011; 19: 783-786

[10] Syriac S, Durie N, Kesterson J et al. Female adnexal tumor of probable Wolffian origin (FATWO) with recurrence 3 years postsurgery. Int J Gynecol Pathol 2011; 30: 231-235
[11] Harada O, Ota H, Takagi K et al. Female adnexal tumor of probable wolffian origin: morphological, immunohistochemical, and ultrastructural study with c-kit gene analysis. Pathol Int 2006; 56: 95-100

[12] Wakayama A, Matsumoto $\mathrm{H}$, Aoyama $\mathrm{H}$ et al. Recurrent female adnexal tumor of probable Wolffian origin treated with debulking surgery, imatinib and paclitaxel/carboplatin combination chemotherapy: A case report. Oncol Lett 2017; 13: 3403-3408

[13] Seracchioli R, Mabrouk M, Solfrini S et al. One-Step Laparoscopic Management of a Female Adnexal Tumor of Wolffian Origin. Case Rep Oncol 2010; 3: 428-433

[14] Deshimaru R, Fukunaga T, Sato T et al. A case of metastatic female adnexal tumor of probable Wolffian origin. Gynecol Oncol Case Rep 2014; 10: $22-24$

[15] Liu Y. Metastatic female adnexal tumor of possible wolffian origin (FATWO) of the appendix demonstrated by FDG PET/CT: the first reported case. Clin Nucl Med 2011; 36: 136-137

[16] Lesin J, Forko-Ilic J, Plavec A et al. Management of Wolffian duct tumor recurrence without chemotherapy. Arch Gynecol Obstet 2009; 280: $855-857$ 